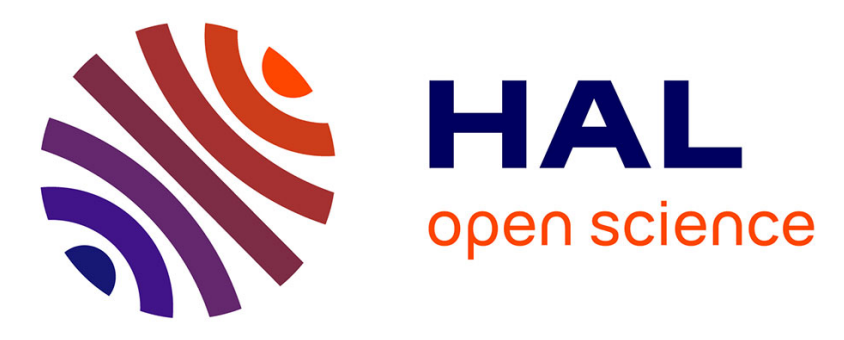

\title{
Cobalt Phthalocyanine Immobilized on Graphene Oxide: An Efficient Visible-Active Catalyst for the Photoreduction of Carbon Dioxide
}

Pawan Kumar, Arvind Kumar, Bojja S Sreedhar, Bir Sain, Siddharth S Ray, Suman L Jain

\section{To cite this version:}

Pawan Kumar, Arvind Kumar, Bojja S Sreedhar, Bir Sain, Siddharth S Ray, et al.. Cobalt Phthalocyanine Immobilized on Graphene Oxide: An Efficient Visible-Active Catalyst for the Photoreduction of Carbon Dioxide. Chemistry - A European Journal, 2014, 20, pp.6154 - 6161. 10.1002/chem.201304189 . hal-01456553

\section{HAL Id: hal-01456553 https://hal.science/hal-01456553}

Submitted on 5 Feb 2017

HAL is a multi-disciplinary open access archive for the deposit and dissemination of scientific research documents, whether they are published or not. The documents may come from teaching and research institutions in France or abroad, or from public or private research centers.
L'archive ouverte pluridisciplinaire HAL, est destinée au dépôt et à la diffusion de documents scientifiques de niveau recherche, publiés ou non, émanant des établissements d'enseignement et de recherche français ou étrangers, des laboratoires publics ou privés. 


\title{
Cobalt Phthalocyanine Immobilized on Graphene Oxide: An Efficient Visible-Active Catalyst for the Photoreduction of Carbon Dioxide
}

\author{
Pawan Kumar, ${ }^{[a]}$ Arvind Kumar, ${ }^{[b]}$ Bojja Sreedhar, ${ }^{[c]}$ Bir Sain, ${ }^{[a]}$ Siddharth S. Ray, ${ }_{1}^{[b]}$ and \\ Suman L. Jain ${ }^{*[a]}$
}

\begin{abstract}
New graphene oxide (GO)-tethered-Co" phthalocyanine complex [CoPc-GO] was synthesized by a stepwise procedure and demonstrated to be an efficient, cost-effective and recyclable photocatalyst for the reduction of carbon dioxide to produce methanol as the main product. The developed GO-immobilized CoPc was characterized by X-ray diffraction (XRD), FTIR, XPS, Raman, diffusion reflection UV/ Vis spectroscopy, inductively coupled plasma atomic emission spectroscopy (ICP-AES), thermogravimetric analysis (TGA), Brunauer-Emmett-Teller (BET), scanning electron microscopy (SEM), and transmission electron microscopy (TEM). FTIR, XPS, Raman, UV/Vis and ICP-AES along with elemental analysis data showed that Co"-Pc complex was successfully grafted on GO. The prepared catalyst was used for the photocatalytic reduction of carbon dioxide by using water as a solvent and triethylamine as the sacrificial donor. Methanol
\end{abstract}

was obtained as the major reaction product along with the formation of minor amount of $\mathrm{CO}(0.82 \%)$. It was found that GO-grafted CoPc exhibited higher photocatalytic activity than homogeneous $\mathrm{CoPc}$, as well as GO, and showed good recoverability without significant leaching during the reaction. Quantitative determination of methanol was done by GC flame-ionization detector (FID), and verification of product was done by NMR spectroscopy. The yield of methanol after $48 \mathrm{~h}$ of reaction by using GO-CoPc catalyst in the presence of sacrificial donor triethylamine was found to be $3781.8881 \mu \mathrm{mol} \mathrm{g}^{-1}$ cat., and the conversion rate was found to be $78.7893 \mu \mathrm{molg}^{-1}$ cat. $\mathrm{h}^{-1}$. After the photoreduction experiment, the catalyst was easily recovered by filtration and reused for the subsequent recycling experiment without significant change in the catalytic efficiency.
Utilization of carbon dioxide as a sustainable $C_{1}$ building block has emerged as an important area of research in last two decades mainly due to the concurrently problems of global warming, as well as depletion of fossil fuels. ${ }^{[1]}$ The effective use of clean and abundant solar energy might provide a viable approach to solve the problems of energy and environmental crisis by a photocatalytic reduction of carbon dioxide to valuable chemicals. Although a number of improved catalytic systems, such as nanosized titanium oxide, titanium oxide doped with transition metals, noble metals, and mixed with another metal oxide have been emerged as potent catalysts for the

[a] P. Kumar, Dr. B. Sain, Dr. S. L. Jain

Chemical Sciences Division, CSIR-Indian Institute of Petroleum

Mohkampur, Dehradun 248005 (India)

Fax: (+91) 135-2660202

E-mail:suman@iip.res.in

[b] A. Kumar, Dr. S. S. Ray

Analytical Sciences Division, CSIR-Indian Institute of Petroleum Mohkampur, Dehradun 248005 (India)

[c] Dr. B. Sreedhar

Inorganic and Physical Chemistry Division

CSIR-Indian Institute of Chemical Technology

Hyderabad, 500607, Andhra Pradesh (India)

Supporting information for this article is available on the WWW under http://dx.doi.org/10.1002/chem.201304189. photoreduction of $\mathrm{CO}_{2}$, but their quantum yields and selectivities of products are low. ${ }^{[2-3]}$ In the recent years, photocatalytic systems, including transition-metal complexes, such as ruthenium(II) polypyridine carbonyl complex, cobalt(II) trisbipyridine, cobalt(III) macrocycles, rhenium and iridium complex with a photosensitizer have emerged to be efficient catalytic systems to reduce $\mathrm{CO}_{2}$ with relatively high quantum yield and high selectivity of products. ${ }^{[4]}$ However, the difficult recovery and non-recycling ability of a homogeneous complex make these systems less attractive. To overcome these problems, immobilization of homogeneous metal complexes to solid support is an obvious way to combine the advantages of homogeneous catalysts, for example, high reactivity, selectivity, and heterogeneous catalysts, such as facile recovery and recycling of the catalyst. ${ }^{[5]}$ In this context, a number of homogeneous photoredox complexes have been supported to various supports, such as $\mathrm{TiO}_{2}$, organic polymers, ion-exchange resins. However, in most of the cases, noncovalent attachment of the metal complex to support materials renders to the leaching of the active species during the reaction. ${ }^{[6]}$

Metallophthalocyanines and their derivatives have been widely used as photosensitizers for various applications in a variety of fields due to their unique properties, such as excellent semiconductivity, photoconductivity, thermal, and chemical 
stability. Most of the studies conducted to date on metal phthalocyanines for photocatalytic reduction of $\mathrm{CO}_{2}$ were performed either in homogeneous solution or by supporting them to other semiconductor materials, such as $\mathrm{TiO}_{2} \cdot{ }^{[7]}$ In this context, Zhou et al. ${ }^{[8]}$ reported the use of in situ synthesized $\mathrm{TiO}_{2} / \mathrm{CoPc}$ nanocomposite for the photocatalytic reduction of carbon dioxide to formic acid, formaldehyde, and methanol.

Graphene oxide (GO), an oxidized form of grapheme, has emerged to be a promising material, particularly as a precursor to prepare reduced $\mathrm{GO}$ ( $\mathrm{rGO}$ ), chemically functionalized graphene, and grapheme-based composite materials. ${ }^{[9,10]}$ Very recently, Hsu et al. ${ }^{[11]}$ have reported $\mathrm{GO}$ as a promising photocatalyst for the conversion of $\mathrm{CO}_{2}$ to methanol with the conversion rate of $0.172 \mu \mathrm{mol} \mathrm{g}^{-1} \mathrm{cat}^{-1} \mathrm{~h}^{-1}$ under visible light.

Herein, we describe the successful synthesis of covalently anchored cobalt phthalocyanine to the $\mathrm{GO}$, its characterization, and use for the photocatalytic reduction of the carbon dioxide to methanol with improved product yield and selectivity. The oxygen functionalities on $\mathrm{GO}$ are targeted for stable and efficient anchoring of CoPc catalyst on nanosheets of GO through covalent attachment. The prepared catalyst exhibited higher photocatalytic activity under visible-light irradiation and gave methanol with improved yield and selectivity. The quantitative and qualitative determination of the methanol formation was performed by GC and ${ }^{1} \mathrm{H}$ NMR spectroscopy.

\section{Synthesis and characterization of catalyst}

$\mathrm{GO}$ was obtained from the oxidation of graphite with $\mathrm{KMnO}_{4}$ and $\mathrm{H}_{2} \mathrm{SO}_{4}$ following the literature procedure. ${ }^{[12]}$ High specific surface area of $\mathrm{GO}$ along with easily accessible ample oxygen functionalities decorated on both side of $\mathrm{GO}$ nanosheets pro- vide great potential as a support material for various catalysts. ${ }^{[13]}$ Prior to the immobilization, the GO was treated with chloroacetic acid to convert the epoxy groups into carboxy $(\mathrm{COOH})$ groups, which were subsequently used for the grafting of $\mathrm{CoPc}$ to the GO surface. The schematic representation of the synthesis of CoPc immobilized on GO (GO-CoPc) is shown in Scheme 1.

The morphology and structure of as-prepared GO and GOCoPc catalyst was investigated by scanning electron microscopy (SEM) and transmission electron microscopy (TEM). As presented in Figure $1 \mathrm{~b}$, the SEM image of GO-CoPc shows twisted

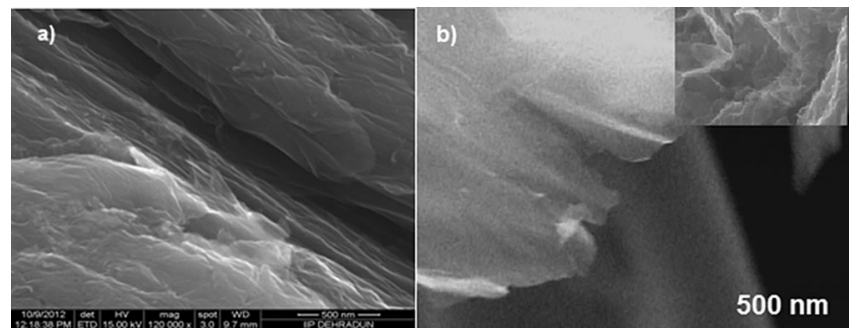

Figure 1. SEM image of a) GO and b) GO-CoPc.

and crumpled nanosheets in an agglomerated phase with lot of wrinkled features of GO-CoPc catalyst. The TEM images shown in Figure $2 \mathrm{a}$ and $\mathrm{b}$ also reveal the nanoscopic features with layered structure of GO-CoPc catalyst (Figure S1 in the Supporting Information). The TEM image of carboxylic group $(\mathrm{COOH})$ containing $\mathrm{GO}$ before immobilization of CoPc is shown in Figure $2 \mathrm{c}$. The dark spots in the TEM image (Figure $2 \mathrm{c}$ ) are probably due to the $\mathrm{COOH}$ functionalities located on the sur-

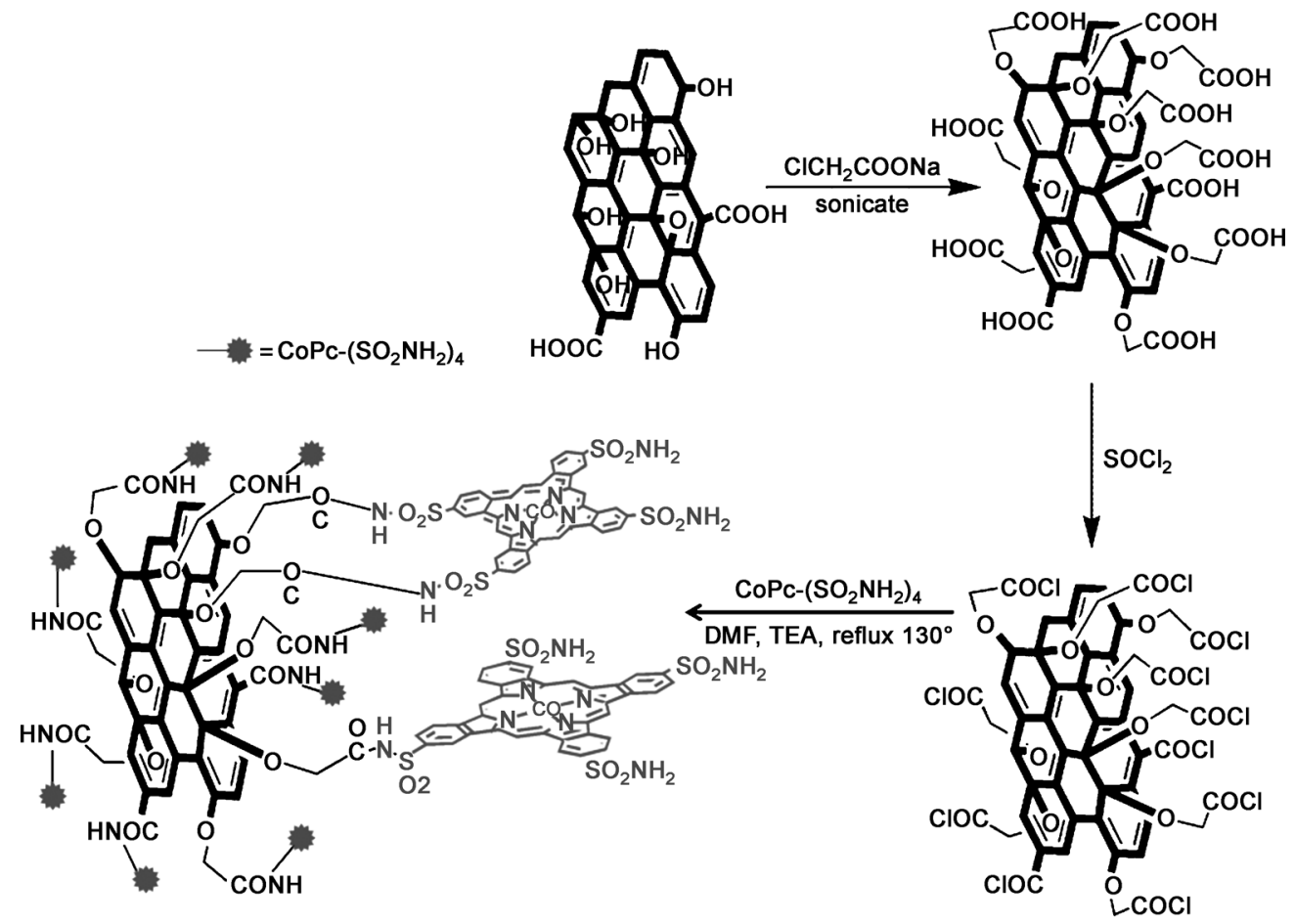

Scheme 1. Synthesis of GO-grafted CoPc. 


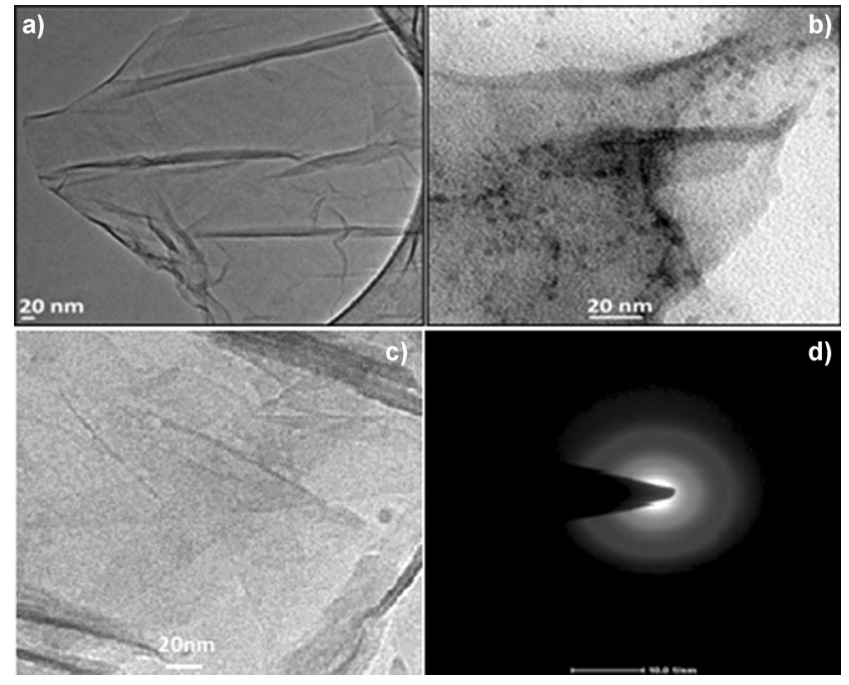

Figure 2. TEM image of a) GO; b) GO-COPc; c) GO-COOH; and d) SAED pattern of GO-CoPc.

face of GO. Selected area electron diffraction pattern of GO$\mathrm{CoPc}$ shows that material was amorphous in nature (Figure $2 \mathrm{~d}$ ).

XRD patterns were used to study the changes in structure (Figure 3). The XRD spectrum of GO shown in Figure 3 a gives characteristic diffraction peak at $10.8^{\circ}(001)$, corresponding to

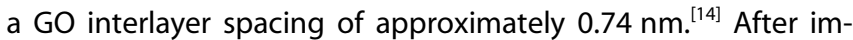
mobilization of $\mathrm{CoPc}$, this peak disappeared, and another

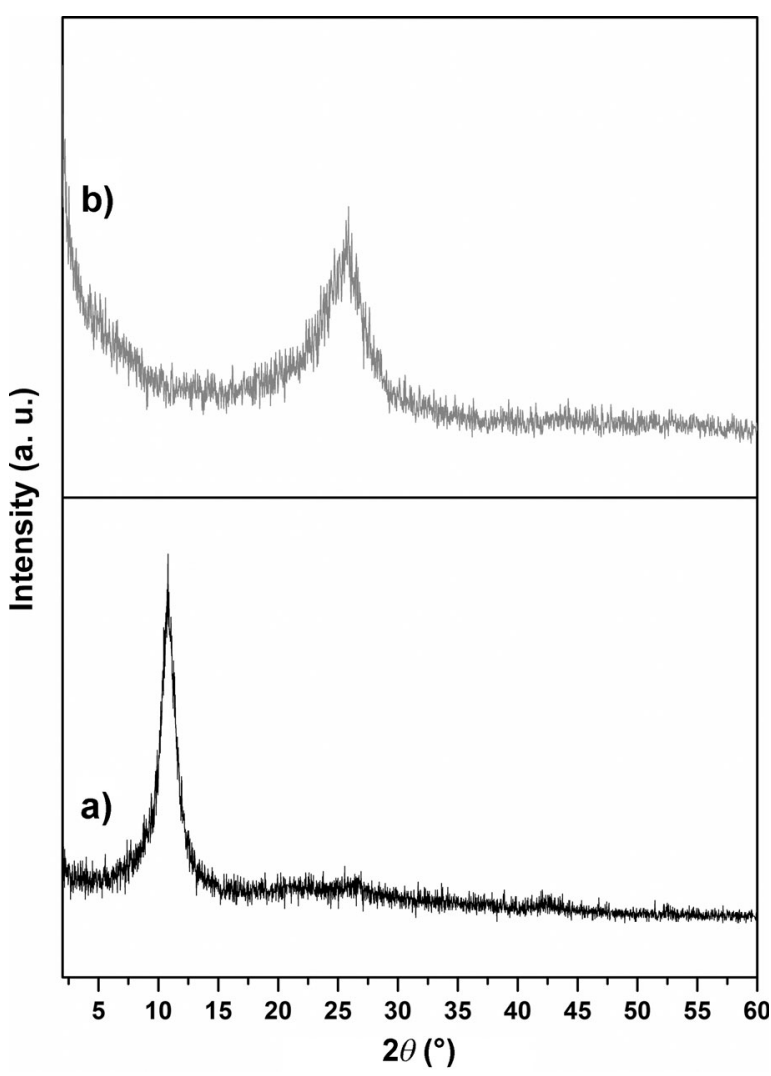

Figure 3. XRD spectra of a) GO and b) GO-CoPc. broad diffraction of graphite (002) at $2 \theta$ value of approximately $26^{\circ}$ appeared, indicating that exfoliation of the layered CoPcGO was obtained. ${ }^{[15]}$

The porosity characteristics of the samples were investigated by measuring the $\mathrm{N}_{2}$ adsorption/desorption isotherms at $77 \mathrm{~K}$ (Figure 4). Total pore volume and surface area of synthesized
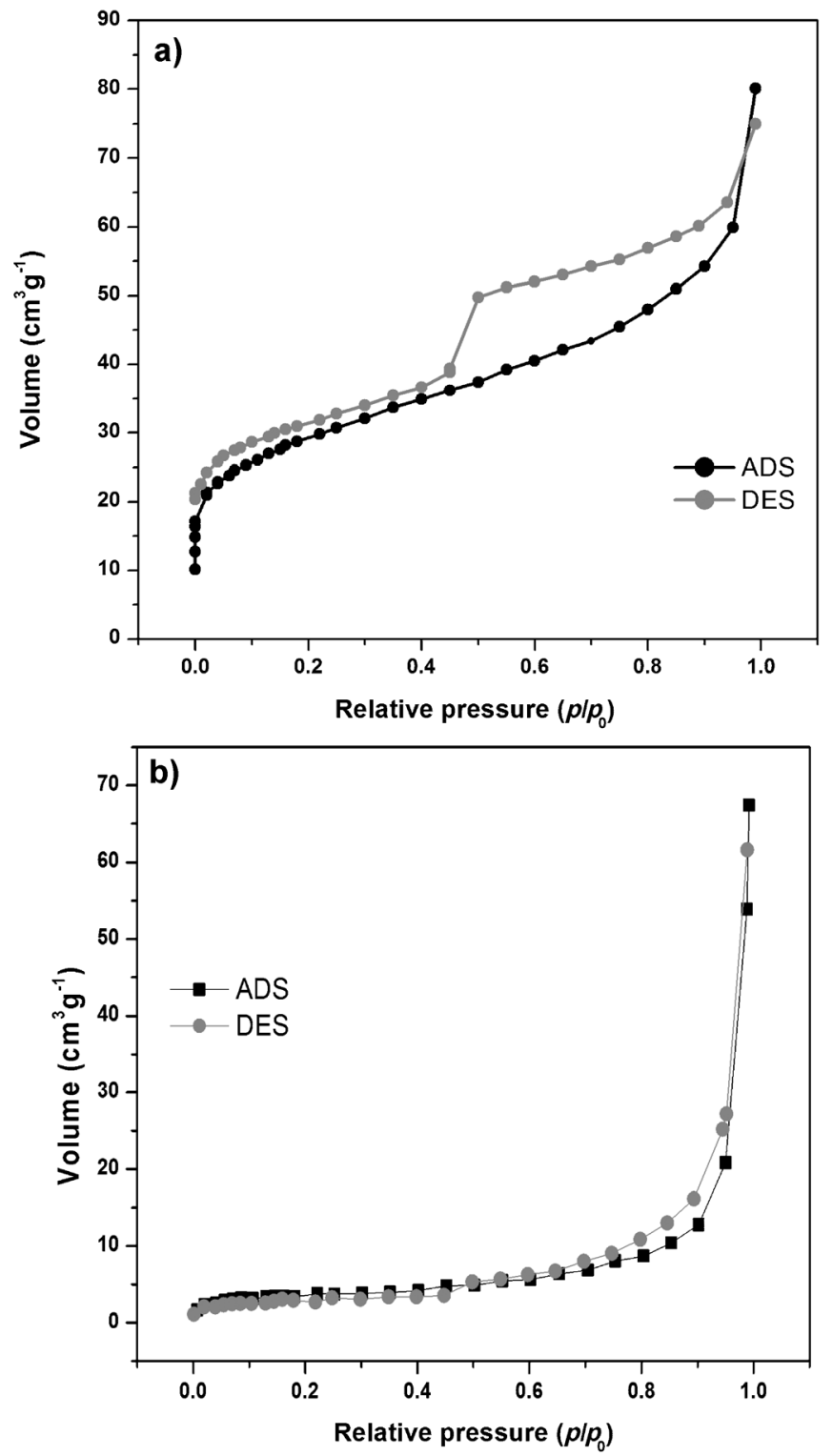

Figure 4. Adsorption/desorption curve of a) GO and b) GO-CoPc.

GO was found to be $0.1212 \mathrm{~cm}^{3} \mathrm{~g}^{-1}$ and $87.247 \mathrm{~m}^{2} \mathrm{~g}^{-1}$, respectively. Total pore diameter of GO was found to be $5.5566 \mathrm{~nm}$ that was in agreement to mesoporous nature. ${ }^{[16]}$ The adsorption/desorption isotherm was of type IV (Figure 4). The negligible $\mathrm{N}_{2}$ adsorption in $\mathrm{GO}$ and $\mathrm{GO}-\mathrm{CoPc}$ suggested the filled interlayer galleries and the restacked graphitic structure in GO. Obtained value of $S_{\text {BET }} 12.34 \mathrm{~m}^{2} \mathrm{~g}^{-1}$ for GO-CoPc suggested successful attachment of CoPc at the surface of GO. Total pore volume and mean pore diameter of GO-CoPc was measured 
to be $0.09 \mathrm{~cm}^{3} \mathrm{~g}^{-1}$ and $30.158 \mathrm{~nm}$, respectively (Figure S2 in the Supporting Information).

The UV/Vis spectra of GO and GO-CoPc are shown in Figure 5. The UV/Vis spectra of CoPc reveals two main bands,

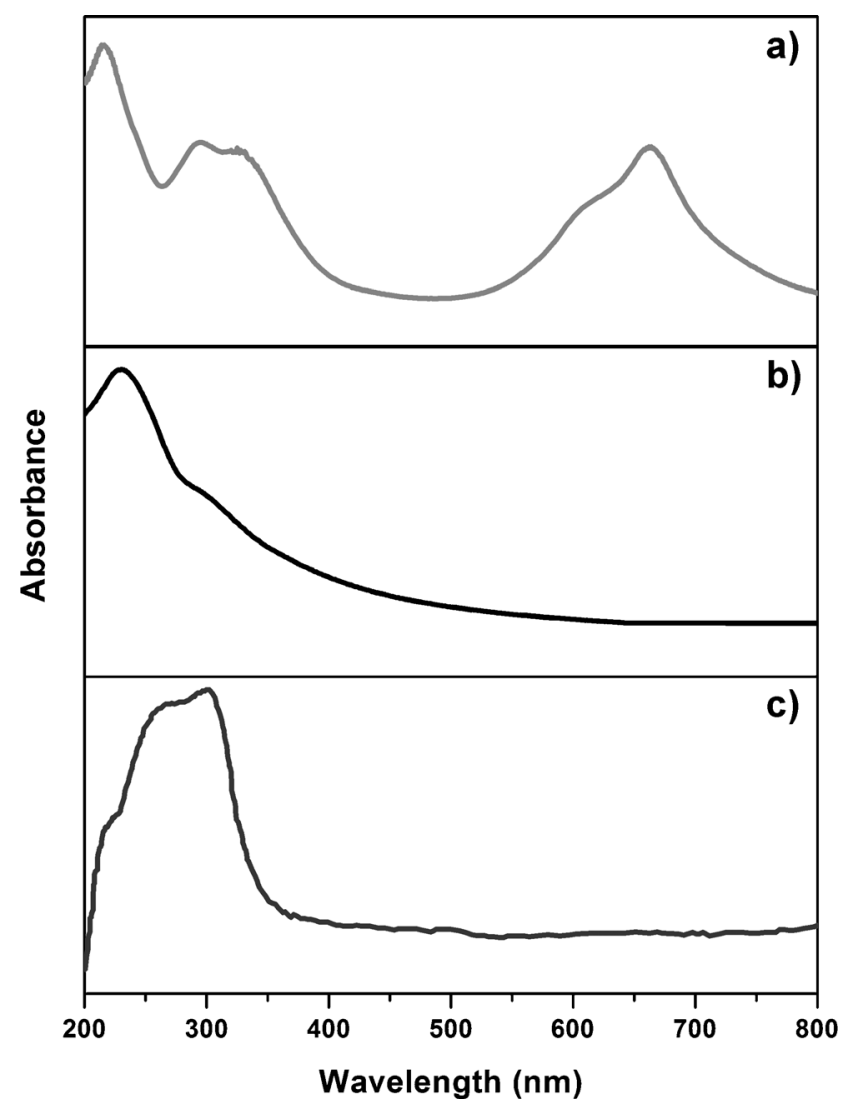

Figure 5. UV/Vis spectra of a) CoPc; b) GO; and c) GO-CoPc.

that is, Soret band at $\lambda=300 \mathrm{~nm}$ and a $\mathrm{Q}$ band at $660 \mathrm{~nm}$ (Figure $5 a) .{ }^{[16]}$ The UV/Vis spectra of GO shows a characteristics peak at nearly $230 \mathrm{~nm}$, which suggests that the synthesized GO possess an ordered graphitic structure due to the $\pi-\pi^{*}$ transition of $\mathrm{C}=\mathrm{C}$ (Figure $5 \mathrm{~b}$ ). Solid UV/Vis spectra of GO-attached $\mathrm{CoPc}$ indicates the significant shifting of the absorption band of GO to a longer wavelength at $300 \mathrm{~nm}$, which clearly indicates that CoPc was successfully attached to GO (Figure $5 \mathrm{c}$ ).

Figure 6 shows the FTIR spectra of as-prepared GO and GOCoPc catalysts. The FTIR spectrum of GO shows vibrational bands at approximately $3410 \mathrm{~cm}^{-1}$ due to hydroxyl stretching vibrations in $\mathrm{COOH}$ and/or intercalated water (Figure $6 \mathrm{~b}$ ). The strong band at $1720 \mathrm{~cm}^{-1}\left(\tilde{v}_{\mathrm{C}=0}\right)$ belongs to carboxylic acid groups, $1630 \mathrm{~cm}^{-1}$-to aromatic $\mathrm{C}=\mathrm{C}$, and the bands at $1227 \mathrm{~cm}^{-1}$ and $1058 \mathrm{~cm}^{-1}$ are attributed to the $\mathrm{C}-\mathrm{OH}$ and alkoxy $\mathrm{C}-\mathrm{O}$ stretching vibrations, respectively. After the immobilization reaction, several new peaks appeared in the FTIR spectrum of GO-CoPc. The characteristic peak of $\mathrm{C}=\mathrm{O}$ at $1720 \mathrm{~cm}^{-1}$ disappeared, and a new peak corresponding to amide $(\mathrm{C}(\mathrm{O}) \mathrm{NH})$ stretching vibration at $\tilde{v}=1654 \mathrm{~cm}^{-1}$ revealed the formation of amide bond between CoPc and GO.

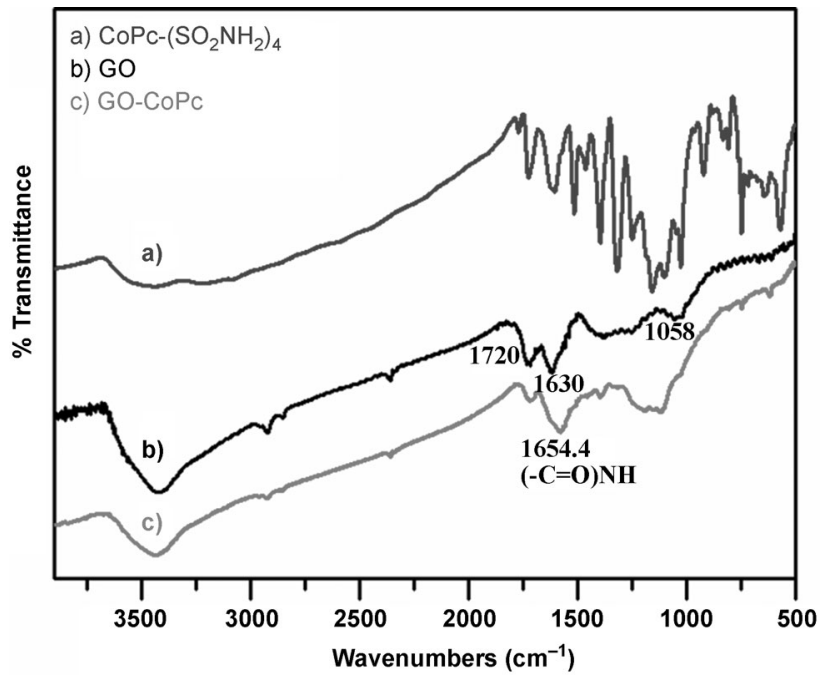

Figure 6. IR spectrum of a) CoPc; b) GO; and c) GO-CoPc.

Further XPS and Raman analyses provided essential and useful information for the covalent attachment of the CoPc to GO. The N1s XPS spectrum of CoPc clearly indicated that the peaks of nitrogen functionalities appeared at 398.95 ( $\mathrm{C}-\mathrm{N}$ bonds), $400.43\left(\mathrm{NH}_{2}\right)$, and $401.58 \mathrm{eV}(\mathrm{C}=\mathrm{N}$ bonds; Figure $7 \mathrm{a})$. In contrast, CoPc-immobilized GO showed the shifting of bands and a considerable intensity enhancement of the peak at $400.69 \mathrm{eV}$ due to the electron-withdrawing effect of GO (Figure $7 \mathrm{~b}$ ).

Furthermore, in the Raman spectrum of GO, there are two prominent bands at about 1363 (D band) and 1608 ( $\mathrm{G}$ band) $\mathrm{cm}^{-1}$ (532 nm excitation; Figure $8 \mathrm{a}$ ). In contrast, both the $D$ and $\mathrm{G}$ bands of GO-CoPc were found to be slightly shifted to the lower-wave numbers, and a new band at $1512 \mathrm{~cm}^{-1}$ was assigned to pyrrole $\mathrm{C}=\mathrm{C}$ stretching mode of CoPc (Figure $8 \mathrm{~b}$ ).

Figure 9 shows the TGA curves of the as-prepared GO and GO-CoPc catalysts. The GO showed initial weight loss near $108^{\circ} \mathrm{C}$, evidently owing to evaporation of water molecules, which are held in the material (Figure 9a). The second significant weight loss was observed in the range of $180-240^{\circ} \mathrm{C}$, and is due to thermal decomposition of oxygen-carrying functionalities. The thermogram of the GO-CoPc catalyst illustrates an exothermic major weight loss over a wide range of temperature $\left(300-500^{\circ} \mathrm{C}\right)$ on account of the slow decomposition of the phthalocyanine moieties: this indicates that the catalyst is sufficiently thermally stable.

\section{The photocatalytic reduction of $\mathrm{CO}_{2}$}

First, the reactivity of the GO, physical 1:1 mixture of $\mathrm{GO}+$ $\mathrm{CoPc}$ and $\mathrm{GO}-\mathrm{CoPc}$, was tested for the photocatalytic reduction of the $\mathrm{CO}_{2}$ by using triethylamine as sacrificial donor and water as a solvent (Figure 10). After the photoreduction, $1 \mu \mathrm{L}$ liquid sample was withdrawn and analyzed in a GC-FID apparatus equipped with a $30 \mathrm{~m}$ long Stabilwax w/Integra-Guard column. Methanol yield was used to evaluate the performance of the catalysts, because it was obtained as the major reduc- 

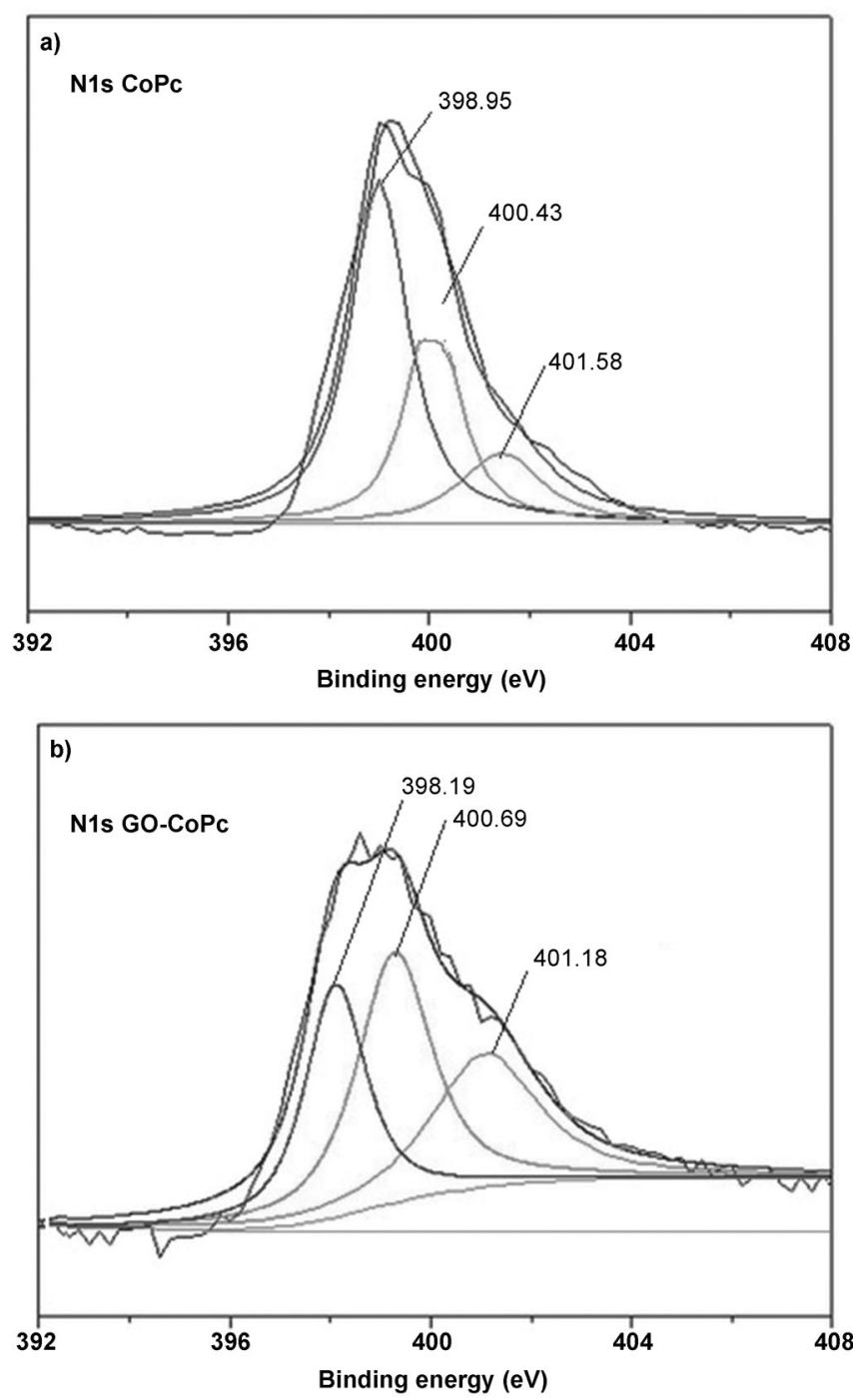

Figure 7. N1 s XPS spectra of a) CoPc and b) GO-CoPc.

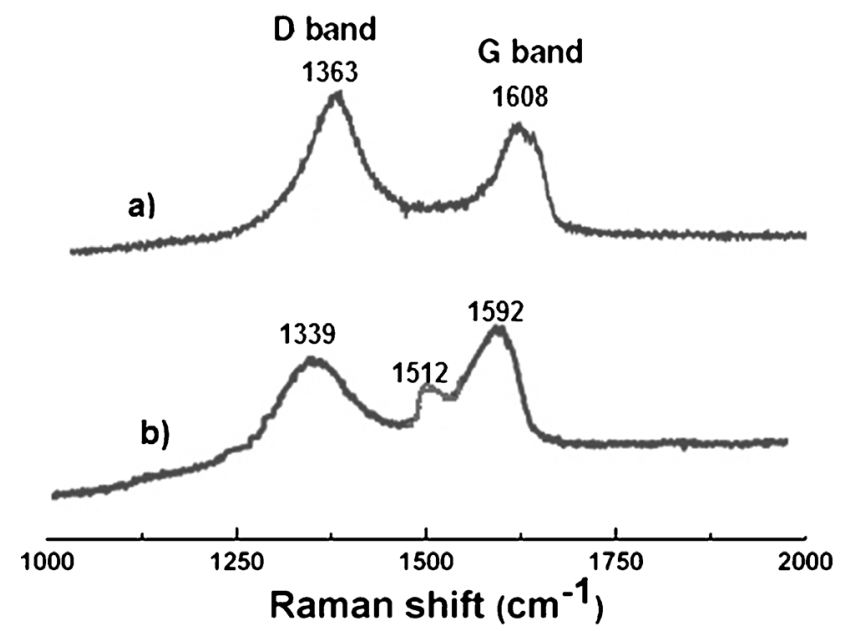

Figure 8. Raman spectra of a) GO and b) GO-CoPc.

tion product. The methanol-formation rate, $R_{\mathrm{MeOH}}\left(\mu \mathrm{mol} \mathrm{g}^{-1}\right.$ cat.) as a function of reaction time was calculated and plotted as

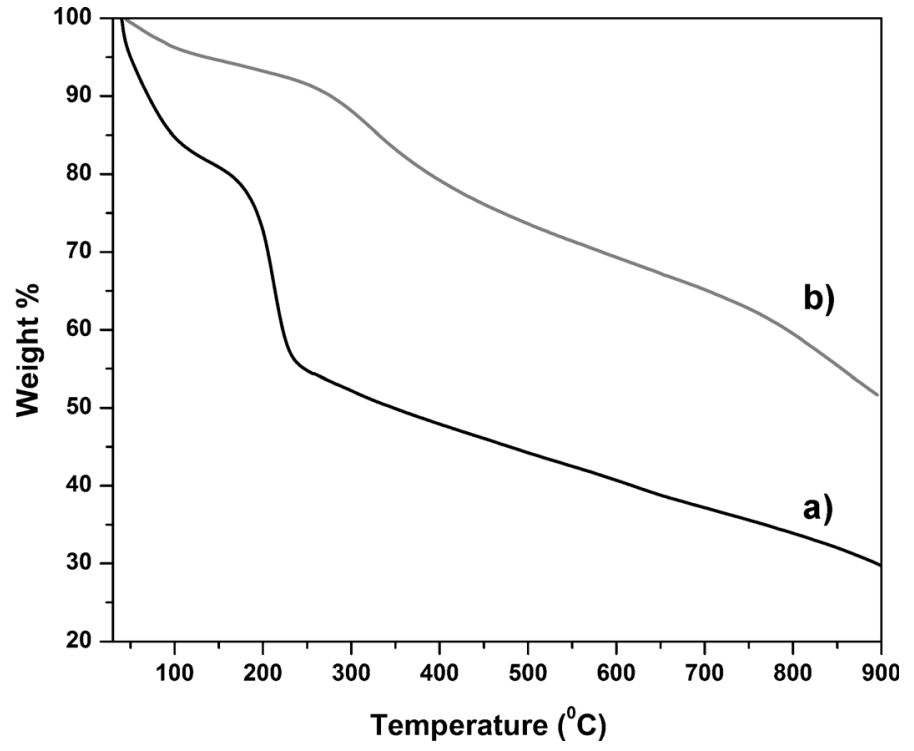

Figure 9. TGA pattern of a) GO and b) GO-CoPc.

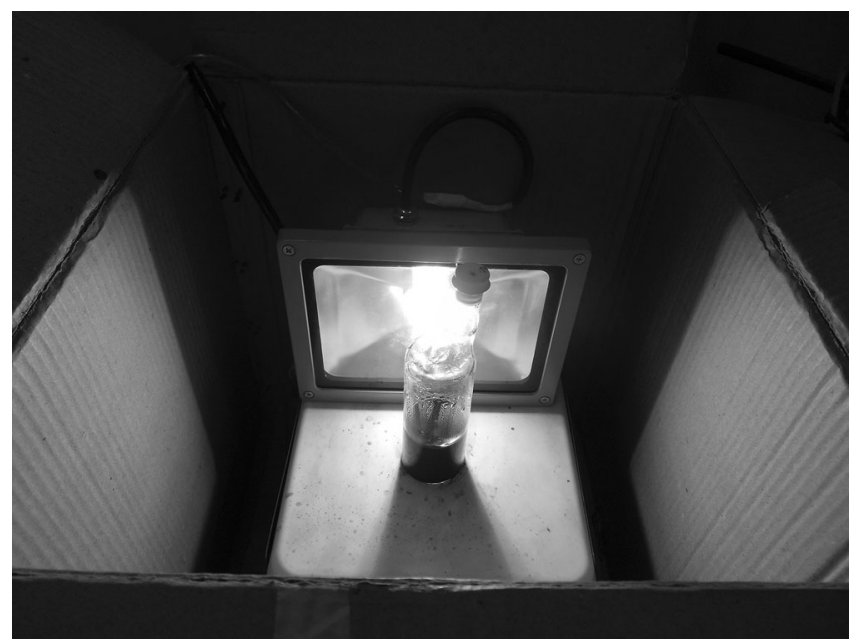

Figure 10. Reaction illumination conditions.

shown in Figure 11. The results clearly indicate that the GOCoPc exhibited higher catalytic activity compared to the $\mathrm{GO}$ and the physical 1:1 mixture of GO-CoPc. After illumination for $48 \mathrm{~h}$ in visible light by using GO-CoPc as catalyst in the presence of triethylamine as sacrificial donor, the yield of methanol was found to be $3781.8881 \mu \mathrm{mol} \mathrm{g}^{-1}$ cat. or production rate $78.7893 \mu \mathrm{mol} \mathrm{g}^{-1} \mathrm{cat}^{-1} \mathrm{~h}^{-1}$. The analysis of gaseous phase by GC showed $99.17 \% \mathrm{CO}_{2}$ and $0.82 \% \mathrm{CO}$ after $48 \mathrm{~h}$ of the reaction. In the GC analysis of gaseous phase, we did not observe the presence of methane and other possible products from reduction of carbon dioxide. Formic acid, formaldehyde, and formate were not detected in liquid-phase analysis. Blank experiments, in the absence of GO-CoPc, as well as in the dark reaction, showed that there was no organic product found for long periods of $\mathrm{CO}_{2}$ photoreduction.

Further, we tested the recycling of the GO-CoPc catalyst for the photoreduction of the $\mathrm{CO}_{2}$. After completion of the reac- 


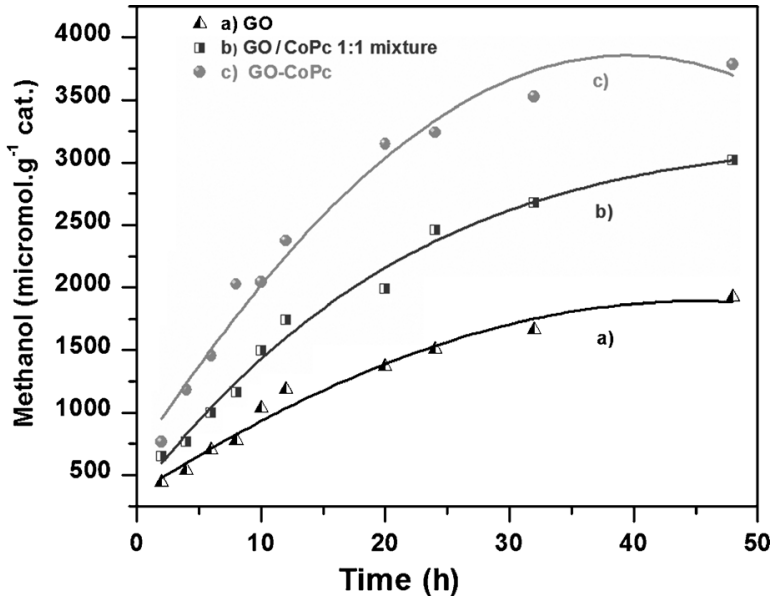

Figure 11. Methanol-conversion rate for a) GO; b) GO:Co-Pc (1:1); and c) GOCoPc.

tion, the catalyst was separated by centrifugation and reused for the subsequent run. ICP analysis of recovered catalyst after one cycle showed cobalt content $1.05 \mathrm{wt} \%$, indicating that small leaching had occurred during the reaction.

Moreover, the possible photocatalytic mechanism of the $\mathrm{GO}-\mathrm{CoPc}$ has been demonstrated for the better understanding of the $\mathrm{CO}_{2}$ photoreduction process (Scheme 2). It is reported in

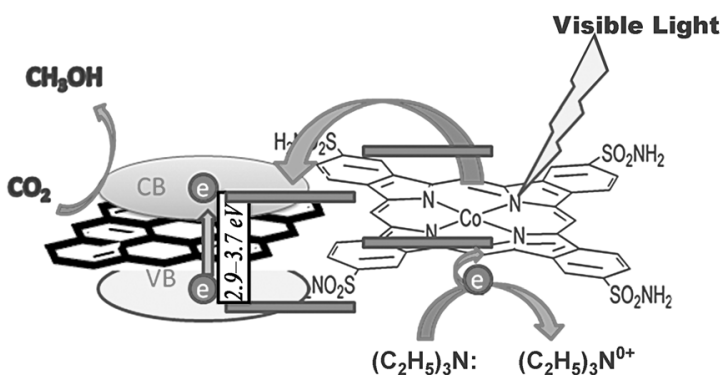

Scheme 2. Possible mechanistic pathway of $\mathrm{CO}_{2}$ reduction.

the literature that presence of various oxy functionalites in $\mathrm{GO}$ creates a 2D network of infintite $\mathrm{sp}^{2}$ and $\mathrm{sp}^{3}$ domains. ${ }^{[18,11]}$ Due to presence of these domains on GO sheet it behaves as it has enormous semiconductor devices on its surface. ${ }^{[19]}$ These $\mathrm{sp}^{2}$ carbon atoms in sheets domain have properties similar to graphene, and electron can flow in this region with minimum resistance: it works like a conduction band. Because the nature of $\mathrm{sp}^{3}$ carbon atoms is such that the associated electrons are not mobile, these domains serve as a valance band. GO works like a semiconductor with valance and conduction bands. ${ }^{[20-22]}$ Because CoPc absorbs strongly in visible region, Pc got excited after absorbing photons and formed $S_{0}$ to $S_{1}$ state. ${ }^{[23]}$ CoPc rapidly transferred excited electrons to conduction band (CB) of $\mathrm{GO}$, and then $\mathrm{CO}_{2}$ adsorbed on $\mathrm{GO}$ surface can accept electrons that are to be reduced. We assumed that the covalent attachment of CoPc to the functional groups of GO provides the reduced band gap between valence and conduction bands of
GO. This significantly promoted the reaction and greatly enhanced the photoefficiency of $\mathrm{CO}_{2}$ with $\mathrm{H}_{2} \mathrm{O}$ to produce $\mathrm{CH}_{3} \mathrm{OH}^{[24]}$ Main advantage of attachment of CoPc to central plane of GO was better charge injection to conduction band of GO. Further, the use of sacrificial donor (triethylamine, TEA) that provides electrons to phthalocyanine also increased yield of methanol. ${ }^{[25]}$

CoPc + visible light $=\mathrm{CoPc}^{*}($ excited singlet state $)$

$\mathrm{CoPc}^{*}=\mathrm{CoPc}^{+}+\mathrm{e}^{-} \mathrm{GO}$ (electron transfer in $\mathrm{CB}$ )

$\mathrm{COPC}^{+}+\mathrm{TEA}=\mathrm{COPC}+\mathrm{TEA}^{+}$

$\mathrm{e}^{-} \mathrm{GO}$ (electron in $\left.\mathrm{CB}\right)+\mathrm{CO}_{2}+\mathrm{H}^{+}=\mathrm{CH}_{3} \mathrm{OH}$

In conclusion, we have demonstrated that GO-immobilized cobalt phthalocyanine is an effective, recyclable, and cost-effective photocatalyst for the photoreduction of $\mathrm{CO}_{2}$ to methanol. Our studies showed that the presence of CoPc to the GO surface play an important role, the methanol conversion rate can be achieved up to $3781.8881 \mu \mathrm{molg}^{-1}$ cat. under visiblelight irradiation for $48 \mathrm{~h}$. These conversion rates are much higher than that of GO. The chemical attachment of CoPc on GO surface provides the higher yield of the desired methanol compared to the physical mixing of the GO and CoPc in 1:1 ratio. CoPc can be promoted by visible light to produce electron-hole pairs. Attachment of CoPc to GO prohibits the recombination of hole and electron. In addition, CoPc rapidly transfers excited electrons to the conduction bands of the $\mathrm{GO}$, which provides the efficient photoreduction of the $\mathrm{CO}_{2}$ with water to produce methanol.

\section{Experimental Section}

\section{Materials}

Graphite flakes, cobalt(II) phthalocyanine (97\%), and triethylamine (99\%) were purchased from Sigma-Aldrich. Potassium permanganate $99.0 \%$, sodium nitrate $99.0 \%$, concentrated sulfuric acid, hydrogen peroxide $(30 \%)$, hydrochloric acid, chloroacetic acid, $\mathrm{NaOH}$, thionyl chloride, chlorosulfonic acid (99\%), acetonitrile, and HPLCgrade water were purchased from Merck (India). All chemicals and solvents were of analytical grade and used as received. Cobaltphthalocyaninetetrasulfonamide complex was synthesized by following the literature procedure. ${ }^{[26]}$

\section{Techniques used}

UV/Vis absorption spectra for GO and GO-CoPc dispersions were recorded with a Perkin-Elmer lambda-19 UV/Vis-NIR spectrophotometer by using a $10 \mathrm{~mm}$ quartz cell. Solid-state spectra were recorded by using $\mathrm{BaSO}_{4}$ as a reference. FTIR analysis was conducted by Perkin-Elmer Spectrum RX-1 IR spectrophotometer. HR-TEM of the GO and GO-CoPc was executed by using FEl-TecnaiG ${ }^{2}$ TwinTEM operating at an acceleration voltage of $200 \mathrm{kV}$. SEM analysis was performed by Jeol Model JSM-6340F. For FE-SEM analysis, aqueous dispersions of GO and GO-CoPc were deposited on the glass slides, whereas very dilute aqueous suspensions were deposited on carbon-coated copper grids for HR-TEM analysis. X-ray powder diffraction (XRD) analyses were carried out by using a Bruker D8 
Advance diffractometer at $40 \mathrm{kV}$ and $40 \mathrm{~mA}$ with $\mathrm{Cu}_{\mathrm{K} \alpha}$ radiation $(\lambda=0.15418 \mathrm{~nm})$. Sample for XRD was prepared by the deposition of well-dispersed graphene-CoPc on glass slide followed by drying; the analysis was performed by using cobalt as the target material. Thermogravimetric analyses (TGA) of these samples were carried out by using a thermal analyzer TA-SDT Q-600. All samples were analyzed in the temperature range of 40 to $900^{\circ} \mathrm{C}$ at a heating rate of $10^{\circ} \mathrm{C} \mathrm{min}^{-1}$ under the nitrogen flow. The porous properties of GO and GO-CoPc catalysts were examined by $\mathrm{N}_{2}$ adsorption/desorption isotherms at $77 \mathrm{~K}$ and the related data (surface area, $S_{\mathrm{BET}}$; pore volume, PV; Micromeritics ASAP 2010) were calculated. XPS measurements were obtained on a KRATOS-AXIS 165 instrument equipped with dual aluminum-magnesium anodes by using $\mathrm{Mg}_{\mathrm{K} \alpha}$ radiation $(h v=1253.6 \mathrm{eV})$ operated at $5 \mathrm{kV}$ and $15 \mathrm{~mA}$ with pass energy $80 \mathrm{eV}$ and an increment of $0.1 \mathrm{eV}$. To overcome the charging problem, a charge neutralizer of $2 \mathrm{eV}$ was applied and the binding energy of $\mathrm{C} 1 \mathrm{~s}$ core level $(\mathrm{BE} \cong 84.6 \mathrm{eV})$ of adventitious hydrocarbon was used as a standard. The XPS spectra were fitted by using a nonlinear square method with the convolution of Lorentzian and Gaussian functions, after a polynomial background was subtracted from the raw spectra. The conversions and selectivity of the products were determined by high-resolution GC-FID (Varian CP-3800). 'H NMR spectra of the products were recorded on $500 \mathrm{MHz}$ by using Bruker Avance-II $500 \mathrm{MHz}$ instrument. ICPAES analysis was carried out by inductively coupled plasma atomic emission spectrometer (ICP-AES, DRE, PS-3000UV, Leeman Labs Inc., USA). Samples for ICP-AES were prepared by leaching out $0.01 \mathrm{~g}$ of sample with $\mathrm{HNO}_{3}$ (conc.), and then heated for $30 \mathrm{~min}$ and volume to $10 \mathrm{~mL}$.

After the photoreduction, the mixture was analyzed by GC. The gaseous phase was analyzed by GC-thermal conductivity detector (TCD) and GC-FID (Agilent $7890 \mathrm{~A}$ GC system) by using a column (RGA, refinery gas analyzer) at the flow rate $\left(\mathrm{H}_{2} 35\right.$, air 350, makeup flow $27 \mathrm{~mL} \mathrm{~min}^{-1}$, for TCD reference flow- $45 \mathrm{~mL} \mathrm{~min}^{-1}$, helium flow $2 \mathrm{~mL} \mathrm{~min}^{-1}$ ), injector temperature $220^{\circ} \mathrm{C}$, TCD detector temperature and FID detector temperature $\left(220^{\circ} \mathrm{C}\right)$. Liquid samples were analyzed with GC-FID model Varian CP3800 (column specification: Stabilwax w/Integra-Guard, length $30 \mathrm{~m}, 0.25 \mathrm{ID}$ ) at the flow rate $0.5 \mathrm{~mL} \mathrm{~min}^{-1}$, injector temp $250^{\circ} \mathrm{C}$, FID detector temperature $275^{\circ} \mathrm{C}$. Autosampler (model no. Varian CP 8410) was used for injecting the same amount of sample $(1 \mu \mathrm{L})$. Calibration curve was plotted with the help of auto sampler by injecting one microliter sample (Figure S3 in the Supporting Information).

\section{Synthesis of graphene oxide (GO)}

Graphene oxide (GO) was synthesized from graphite flakes by using modified Hummers methods. ${ }^{[11]}$ In a typical synthesis, concentrated $\mathrm{H}_{2} \mathrm{SO}_{4}(34 \mathrm{~mL})$ was added into a flask containing graphite flakes $(1 \mathrm{gm})$ and sodium nitrate $(0.75 \mathrm{gm})$ under stirring at $0{ }^{\circ} \mathrm{C}$ (ice bath). Approximately $4.5 \mathrm{gm}$ of $\mathrm{KMnO}_{4}$ was added gently over $20 \mathrm{~min}$ to the mixture and kept under stirring at RT for five days. After that, diluted $\mathrm{H}_{2} \mathrm{SO}_{4}(50 \mathrm{~mL}, 5 \mathrm{wt} \%)$ was added into the mixture and heated to $90^{\circ} \mathrm{C}$ under continuous stirring for $2 \mathrm{~h}$. Then, $\mathrm{H}_{2} \mathrm{O}_{2}$ (30 wt \%; $2.7 \mathrm{~mL}$ ) was added into the solution and stirred for another $2 \mathrm{~h}$ under ambient conditions. After completion of the reaction, the mixture was centrifuged $(6000 \mathrm{rpm}, 15 \mathrm{~min})$ and washed with $\mathrm{H}_{2} \mathrm{SO}_{4}(3 \mathrm{wt} \%), \mathrm{H}_{2} \mathrm{O}_{2}(0.5 \mathrm{wt} \%)$, and $\mathrm{HCl}(3 \mathrm{wt} \%)$, and then repeatedly washed with distilled water, until the $\mathrm{pH}$ of the filtrate became neutral. Finally, the prepared GO was dispersed in distilled water and the homogeneous GO dispersion was then centrifuged and filtered.

\section{Synthesis of carboxylated $\mathrm{GO}^{[27]}$}

In a typical experiment, GO (200 mg) was dispersed in deionized water $(100 \mathrm{~mL})$ by using ultrasonicator to give a concentration of $2 \mathrm{mg} \mathrm{mL}^{-1}$. The obtained suspension was treated with $\mathrm{NaOH}$ $(1.2 \mathrm{~g})$ and chloroacetic acid $(1.0 \mathrm{~g})$ for $3 \mathrm{~h}$ over ultrasonicator bath to convert the $\mathrm{OH}$ groups into $\mathrm{COOH}$ groups. The resulting $\mathrm{GO}-$ $\mathrm{COOH}$ product was neutralized by using a dilute $\mathrm{HCl}$ solution and purified by repeated washing with deionized water and dried under vacuum.

\section{Immobilization of CoPc-tetrasulfonamide to carboxylated $\mathbf{G O}^{[28,29]}$}

Carboxylated GO (GO-COOH; $200 \mathrm{mg})$ was added in DMF $(1 \mathrm{~mL})$ and treated with excess thionyl chloride at $65^{\circ} \mathrm{C}$ for $12 \mathrm{~h}$ to obtain its acyl chloride derivative. Unreacted thionyl chloride was removed by vacuum distillation. The product was washed with THF (three times) and vacuum dried. The obtained GO-Cl (100 mg) was heated at reflux with cobalt phthalocyanine tetrasulfonamide [Co$\mathrm{Pc}-\left(\mathrm{SO}_{2} \mathrm{NH}_{2}\right)_{4}$ complex $(100 \mathrm{mg})$ in DMF under nitrogen atmosphere. The GO-immobilized CoPc complex was separated from the mixture by filtration, washed with ethanol (3-4 times) by using centrifugation and membrane filtration. The GO immobilized CoPc complex was dried in an oven. The analytical values for the GOsupported CoPc were found to be C 59.67, H 3.073, N 5.468, and S $4.75 \%$. The cobalt content in synthesized GO-CoPc was estimated by ICP-AES analysis, and the value was found to be $1.13 \mathrm{wt} \%$ Co. Based on the value of cobalt, the loading of the CoPc in GO-CoPc was found to be $2.3 \mathrm{mmolg}^{-1}$.

\section{Photocatalytic $\mathrm{CO}_{2}$-reduction experiment}

Photocatalytic experiment was performed in borosil cylindrical vessel $(100 \mathrm{~mL})$ of $5 \mathrm{~cm}$ diameter (Figure 1). Photoirradiation was carried out under visible light by using $20 \mathrm{~W}$ white cold LED flood light (model no. HP-FL-20W-F-Hope LED Opto-Electric Co., Ltd.). Intensity of the light at vessel was measured by intensity meter and was found to be $75 \mathrm{Wm}^{-2}$. The vessel was charged initially with water $(40 \mathrm{~mL})$ and triethylamine $(10 \mathrm{~mL})$, and then the solution was degassed by continuous purging of nitrogen for $15 \mathrm{~min} . \mathrm{CO}_{2}$ was bubbled through the solution for at least $30 \mathrm{~min}$ to saturate the solution, then catalyst $(100 \mathrm{mg})$ was added to the above-described solution. The vessel was tightly closed during the reaction and stirred continuously by a magnetic stirring bar to prevent sedimentation of the catalyst. Samples were collected after every $2 \mathrm{~h}$ by using a long needle, and the catalyst was removed with syringe filter (2 $\mathrm{nm}$ PTFE, $13 \mathrm{~mm}$ diameter). Quantitative determination was done by using GC-FID (flow rate $0.5 \mathrm{~mL} \mathrm{~min}^{-1}$, injector temperature $250^{\circ} \mathrm{C}$, FID detector temperature $275^{\circ} \mathrm{C}$ ). A calibration curve was prepared for quantification and for confirmation of linear response of GC-FID system.

Blank reactions were conducted to ensure that methanol production was due to the photoreduction of $\mathrm{CO}_{2}$ and to eliminate surrounding interference. One blank was Vis-illuminated without the catalyst, and another one was kept in the dark with the catalyst and $\mathrm{CO}_{2}$ under the same experimental conditions. An additional blank test was Vis-illuminated with the catalyst filling $\mathrm{N}_{2}$ rather than $\mathrm{CO}_{2}$. No product was detected in the above-described three blank tests. 


\section{Acknowledgements}

We kindly acknowledge Director, CSIR-IIP for his permission to publish these results. P.K. and A.K. are thankful to CSIR, New Delhi for their research fellowships. Analytical department of the Institute is kindly acknowledged for providing support in analysis.

Keywords: carbon dioxide reduction - cobalt · heterogeneous catalysis - photochemistry

[1] M. Aresta, D. Dibenedetto, Dalton Trans. 2007, 2975-2992.

[2] G. A. Olah, Angew. Chem. 2013, 125, 112-116; Angew. Chem. Int. Ed. 2013, 52, 104-107.

[3] A. Dhakshinamoorthy, S. Navalon, A. Corma, H. Garcia, Energy Environ. Sci. 2012, 5, 9217-9233.

[4] L. Liu, F. Gao, H. Zhao, Y. Li, Appl. Catal., B 2013, 134, 349-358.

[5] A. J. Morris, G. J. Meyer, E. Fujita, Acc. Chem. Res. 2009, 42, 1983-1994.

[6] Z. Guo, C. Shao, M. Zhang, J. Mu, Z. Zhang, P. Zhang, B. Chen, Y. Liu, J. Mater. Chem. 2011, 21, 12083-12088.

[7] S. Liu, Z. Zhao, Z. Wang, Photochem. Photobiol. Sci. 2007, 6, 695-700.

[8] X.-T. Zhou, H.-B. Ji, X.-J. Huang, Molecules 2012, 17, 1149-1158.

[9] Z. Zhao, J. Fan, M. Xie, Z. Wang, J. Cleaner Prod. 2009, 17, 1025-1029.

[10] X. Huang, X. Qi, F. Boey, H. Zhang, Chem. Soc. Rev. 2012, 41, 666-686.

[11] H.-C. Hsu, I. Shown, H.-Y. Wei, Y.-C. Chang, H.-Y. Du, Y.-G. Lin, C.-A. Tseng, C.-H. Wang, L.-C. Chen, Y.-C. Lind, K.-H. Chen, Nanoscale 2013, 5, $262-$ 268

[12] W. S. Hummers, R. E. Offeman, J. Am. Chem. Soc. 1958, 80, 1339-1339.

[13] J. Pyun, Angew. Chem. 2011, 123, 46-48; Angew. Chem. Int. Ed. 2011, $50,46-48$.
[14] Q. Du, M. Zheng, L. Zhang, Y. Wang, J. Chen, L. Xue, W. Dai, G. Ji, J. Cao, Electrochim. Acta 2010, 55, 3897.

[15] K. Gotoh, T. Kinumoto, E. Fujii, A. Yamamoto, H. Hashimoto, T. Ohkubo, A. Itadani, Y. Kuroda, H. Ishida, Carbon 2011, 49, 1118-1125.

[16] J. Rouquerol, D. Avnir, C. W. Fairbridge, D. H. Everett, J. M. Haynes, N. Pernicone, J. D. F. Ramsay, K. S. W. Sing, K. K. Unger, Pure Appl. Chem. 1994, 66, 1739-1758.

[17] S. Pochekailov, D. Rais, S. Nespurek, J. Rakusan, M. Karaskova, J. Optoelectron. Adv. Mater. 2007, 19, 479-485.

[18] A. Adán-Más, D. Wei, J. Nanomater. 2013, 3, 325-356.

[19] G. Eda, M. Chhowalla, Adv. Mater. 2010, 22, 2392-2415.

[20] D. Chen, H. Zhang, Y. Liu, J. Li, Energy Environ. Sci. 2013, 6, 1362-1387.

[21] G. Eda, C. Mattevi, H. Yamaguchi, H. K. Kim, M. Chhowalla, J. Phys. Chem. C 2009, 113, 15768-15771.

[22] K. P. Loh, Q. Bao, G. Eda, M. Chhowalla, Nat. Chem. 2010, 2, 1015-1024.

[23] R. C. Swanson, J. Cleaner Prod. 1996, 4, 232-233.

[24] H. Yang, C. Guo, G. H. Guai, Q. Song, S. P. Jiang, C. M. Li, ACS Appl. Mater. Interfaces 2011, 3, 1940-1945.

[25] J. Grodkowski, P. Neta, J. Phys. Chem. A 2000, 104, 1848-1853.

[26] G. Das, B. Sain, S. Kumar, M. O. Garg, G. M. Dhar, Catal. Today 2009, 141 $152-156$.

[27] X. Sun, Z. Liu, K. Welsher, J. T. Robinson, A. Goodwin, S. Zaric, H. Dai, Nano Res. 2008, 1, 203-212.

[28] R. Yamuna, S. Ramakrishnan, K. Dhara, R. Devi, N. K. Kothurkar, E. Kirubha, P. K. Palanisamy, J. Nanopart. Res. 2013, 15, 1399-1408.

[29] Y. Yu, M. Zhou, W. Shen, H. Zhang, Q. Cao, H. Cui, Carbon 2012, 50, $2539-2545$.

Received: October 28, 2013

Revised: February 17, 2014

Published online on April 2, 2014 